\title{
Rancang Bangun Aplikasi Panduan Pariwisata Di Kabupaten Banyuwangi Mobile Berbasis Android
}

\author{
Wira Shilviana Hanum ${ }^{1}$, dan Aries Saifudin ${ }^{2}$ \\ 1,2Teknik Informatika, Universitas Pamulang, Tangerang Selatan, Banten, Indonesia \\ email: ${ }^{1}$ wirahanum1@gmail.com, ${ }^{2}$ aries.saifudin@unpam.ac.id
}

\begin{abstract}
Tourism is a very important sector for the development of a region and tourism is one of the means of promotion to introduce the beauty of nature and the uniqueness of the culture in the area. Including for Banyuwangi Regency which is one of the regencies in East Java Province. This regency has many objects or tourist destinations which are a mainstay and the development of the tourism sector must be accompanied by the development of information technology. Smartphone is one form of technological development and one of the most popular smartphone technology bases based on its operating system is Android.The use of android smartphones in the development of the world of tourism in the information technology era is important for the public and tourists to have knowledge about objects or tourist destinations that will be targeted. In supporting the needs of the tourism information system in Banyuwangi Regency, an Android-based application was created. An application on an android smartphone that suits the needs of travelers equipped with interesting features. This application contains information about tourist objects that are equipped with visual media such as pictures, videos and Google Maps facilities to facilitate in finding tourist locations that will be addressed by the public and tourists.
\end{abstract}

\section{Keywords: Tourism, Banyuwangi Regency, Information Technology, Smartphones, Android}

\section{Pendahuluan}

Pariwisata merupakan sektor yang sangat penting bagi perkembangan suatu daerah, pariwisata merupakan salah satu sarana promosi untuk memperkenalkan keindahaan alam maupun keunikan budaya di daerah tersebut, berkembangnya sektor pariwisata di suatu negara akan menarik sektor lain untuk berkembang pula karena produk-produknya diperlukan untuk menunjang industri pariwisata, seperti sektor pertanian, peternakan, perkebunan, kerajinan rakyat, peningkatan kesempatan kerja, dan lain sebagainya (Udayana, Wirawan, \& Sunarya, 2015).

Begitu juga halnya pada Kabupaten Banyuwangi yang merupakan salah satu Kabupaten di Provinsi Jawa Timur yang sedang tumbuh pada sektor pariwisatanya akhir-akhir ini. Kabupaten berjuluk "The Sunrise of Java" ini terletak di Ujung Timur Pulau Jawa (Haidar, 2017). Menjadikan Kabupaten ini memiliki banyak objek atau destinasi wisata yang menjadi andalan, berkembangnya sektor pariwisata harus dibarengi pula dengan perkembangan teknologi informasi.

Untuk memenuhi kebutuhan informasi akhirnya mendorong pemikiran manusia untuk mengembangkan teknologi sehingga memberikan kemudahan dalam kehidupan manusia (Sulihati \& Andriyani, 2016). Begitu pula, Teknologi informasi membantu pekerjaan dengan menyediakan informasi dan melakukan berbagai tugas yang berhubungan dengan pengolahan informasi. Pemanfaatan teknologi informasi telah mencakup berbagai bidang, mulai dari bidang ekonomi, bisnis sampai pendidikan (Ermatita, 2016). Termasuk dalam bidang pariwisata yang membutuhkan informasi yang terpercaya, dan cepat dengan begitu masyarakat dan wisatawan dapat dengan mudah mengetahui informasi seputar objek-objek wisata yang akan di kunjungi khususnya di daerah Kabupaten Banyuwangi.

Dalam hal ini pemerintah Kabupaten Banyuwangi melalui dinas kepariwisataan melakukan banyak upaya agar masyarakat dan wisatawan dapat dengan mudah mengetahui informasi seputar objek-objek atau destinasi wisata di wilayah tersebut dengan membuat situs website resmi kepariwisataan.

Maka dibuatlah aplikasi berbasis android ini sebagai pilihan lain kepada masyarakat dan wisatawan pengguna smartphone android yang akan melakukan perjalanan ke objek wisata yang ada di Kabupaten Banyuwangi. Suatu aplikasi pada smartphone android yang sesuai dengan kebutuhan wisatawan yang dilengkap dengan fitur-fitur lain. Aplikasi ini berisikan informasi tentang objekobjek wisata yang dilengkapi dengan media visual 
seperti gambar, video serta fasilitas Google Maps guna memudahkan dalam mencari lokasi wisata yang akan dituju oleh masyarakat dan wisatawan.

\section{Penelitian Terkait}

Kabupaten Lingga memiliki 94 objek wisata bahari (pariwisata berobjek laut dan isinya) yang berpotensi untuk dikembangkan. Sejauh ini informasi tentang Kabupaten Lingga hanya tersedia di blog dan website yang tidak resmi dari pemerintah. Berdasarkan permasalahan tersebut, Pendekatan pengembangan sistem yang digunakan dalam penelitian ini adalah Object Oriented Analysis and Design (OOAD) dengan Unified Modeling Language (UML) sebagai modelnya (Muttaqin, Permana, \& Salisah, 2017).

Kabupaten Banggai Kepulauan memiliki lokasi pariwisata yang bervariasi, namun penyebaran informasi pesona wisata ini masih secara manual melalui brosur, poster, dan lain-lain. Metode pengembangan sistem yang digunakan adalah Waterfall Modeling. Hasil penelitian ini menyimpulkan sistem informasi pariwisata pantai berbasis website dapat mengelola data-data pariwisata yang ada secara efektif dan efisien serta dapat diakses dengan cepat dan mudah untuk memberikan informasi tentang pariwisata pantai yang ada di Kabupaten Banggai Kepulauan (Mertayasa \& Yambese, 2017).

\section{Sistem Usulan}

Pada sistem yang akan dibuat diusulkan beberapa hal yang bertujuan untuk memberikan alternatif layanan informasi pariwisata di Banyuwangi. Sistem yang diusulkan akan dibuat menggunakan bahasa pemrogramman Java, Android Studio sebagai IDE (Integrated Development Environment), dan SQL sebagai media penyimpanan data (database).

Rancang sistem secara umum dilakukan dengan maksud untuk memberikan gambaran umum tentang sistem yang baru atau sistem yang akan diusulkan. Rancangan ini mengidentifikasi komponen komponen sistem informasi yang dirancang secara rinci. Perancangan sistem dilakukan dengan membuat rancangan basis data dan rancangan aplikasi.

\section{Perancangan Basis Data (Database)}

Perancangan basis data bertujuan untuk menggambarkan hubungan antardata, atribut dan data yang akan disimpan, dan kebutuhan ruang penyimpanan. Perancangan basis data dibuat untuk mendapatkan struktur yang dapat mempermudah dan mempercepat dalam mengakses dan memanipulasi data serta bebas dari redudansi data. Hasil perancangan basis data harus dapat mengakomodir kebutuhan saat ini dan masa depan (Gat, 2015).

Rancangan basis data dibuat menggunakan notasi Entity Relationship Diagram (ERD). Rancangan basis data aplikasi panduan pariwisata di Kabupaten Banyuwangi berbasis android ditunjukkan pada Gambar 1.

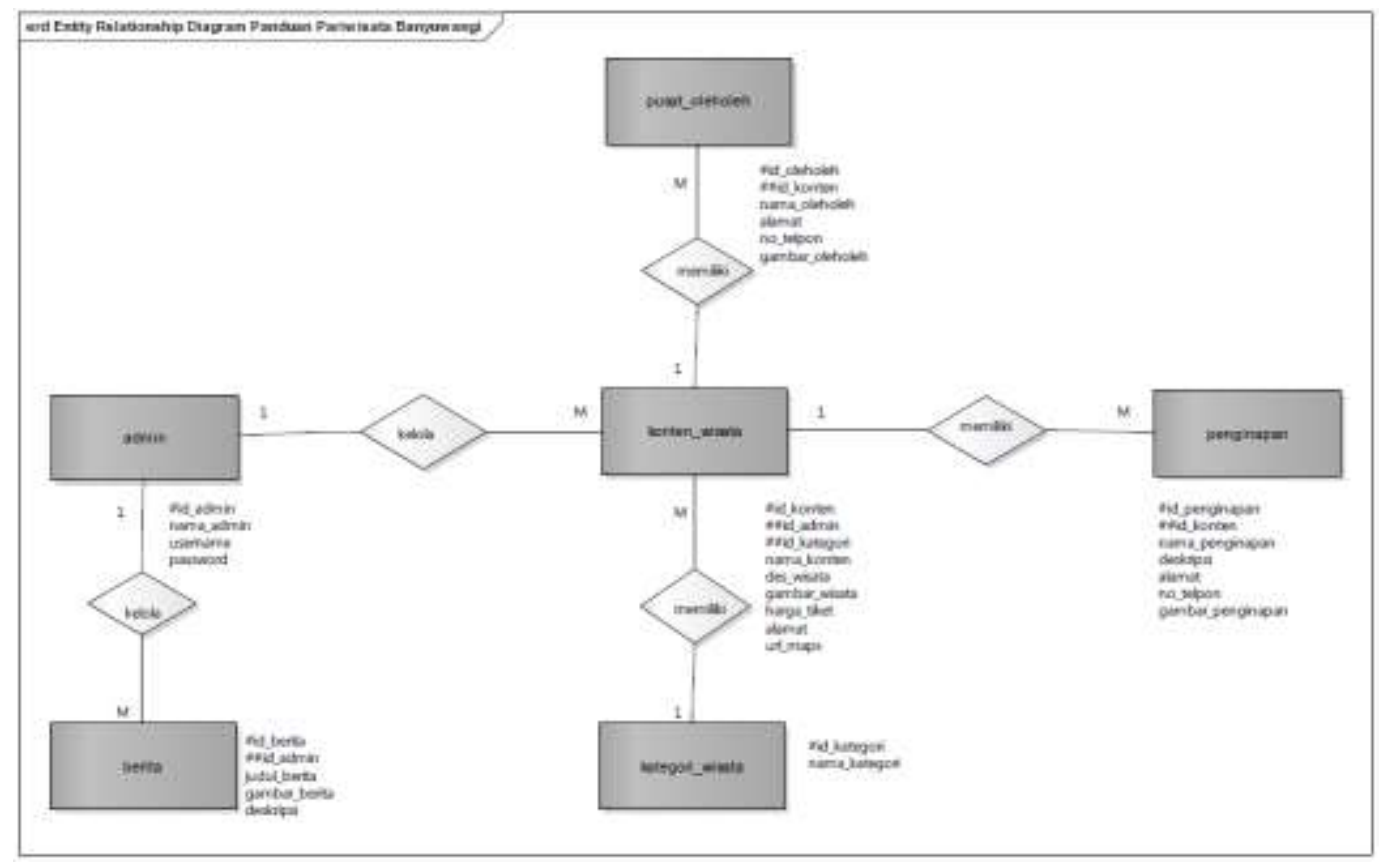

Gambar 1 Rancangan Basis Data Aplikasi Panduan Pariwisata di Kabupaten Banyuwangi 


\section{Perancangan Aplikasi}

Rancangan aplikasi dibuat untuk memberikan gambaran bisnis proses dari aplikasi. Rancangan aplikasi ditujukan untuk beberapa stakeholder, misalnya pimpinan proyek, pengguna, pemrogram, dan penguji. Agar rancangan mudah dipelajari dan dipahami maka sebaiknya menggunakan notasi standar.

Unified Modeling Language (UML) merupakan notasi pemodelan dalam mengembangkan sistem berorientasi objek dan juga merupakan alat untuk mendukung pengembangan sistem (Hendini, 2016). Sehingga pada perancangan aplikasi panduan pariwisata di Kabupaten Banyuwangi ini digunakan UML.

Untuk menggambarkan fungsi dan pengguna aplikasi secara umum digunakan Use Case Diagram. Use Case Diagram merupakan gambaran interaksi di antara komponen-komponen aplikasi yang memperkenalkan bagaimana interaksinya dengan pengguna. Use Case Diagram digunakan untuk mengetahui fungsi apa saja yang ada di dalam sistem informasi dan siapa saja yang berhak menggunakan fungsi-fungsi tersebut (Hendini, 2016). Use Case Diagram Panduan Pariwisata Banyuwangi ditunjukkan pada Gambar 2.

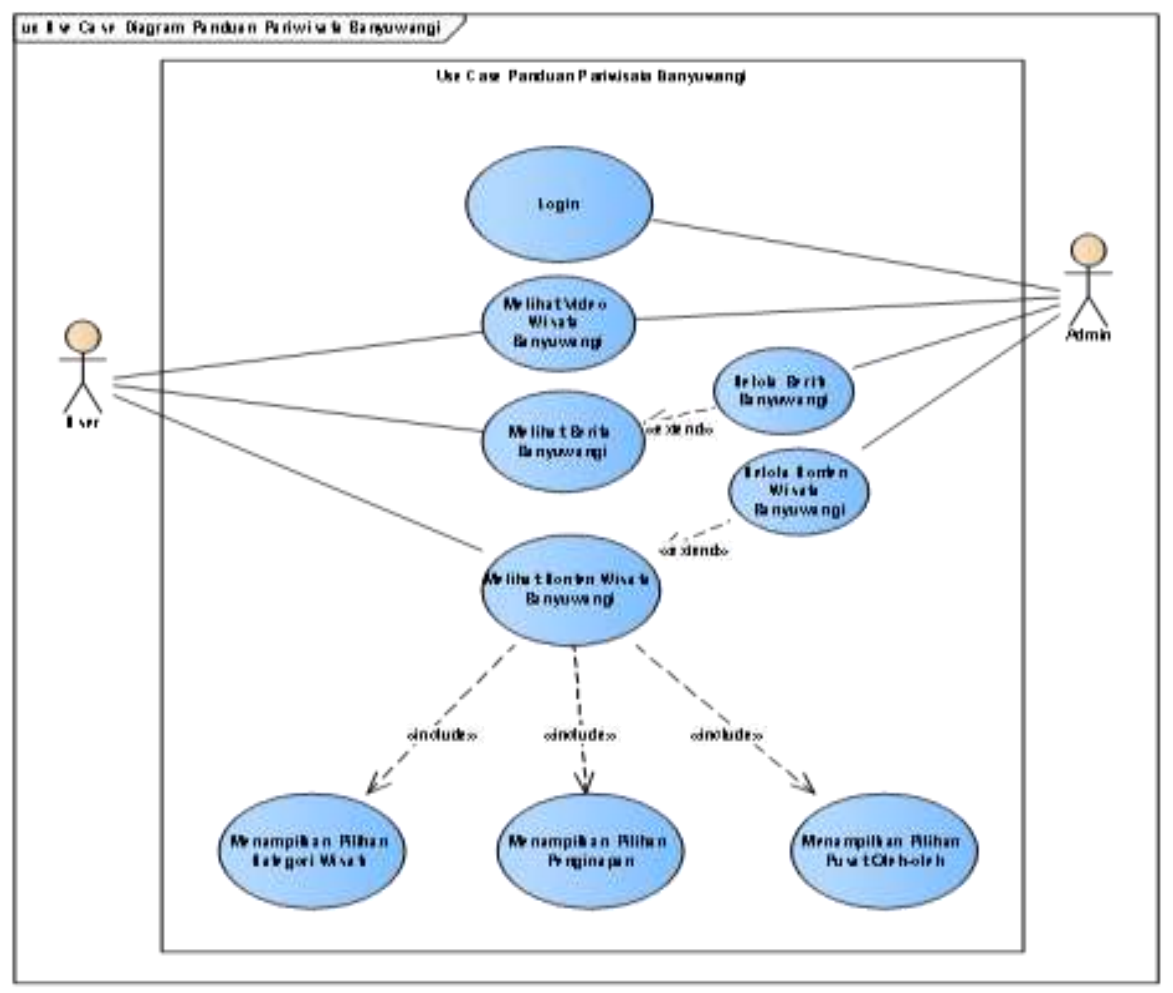

Gambar 2 Use Case Diagram Aplikasi Panduan Pariwisata di Kabupaten Banyuwangi

Model pengembangan sistem yang digunakan dalam pengembangan aplikasi ini adalah model waterfall. Model waterfall merupakan pengembangan sistem informasi yang bersifat sistematik (susunan) dan sekuensial (rangkaian) (Anggraini, Ardiyanty, \& Widiyanto, 2014). Model waterfall memiliki tahapan-tahapan yang ditunjukkan pada Gambar 3.

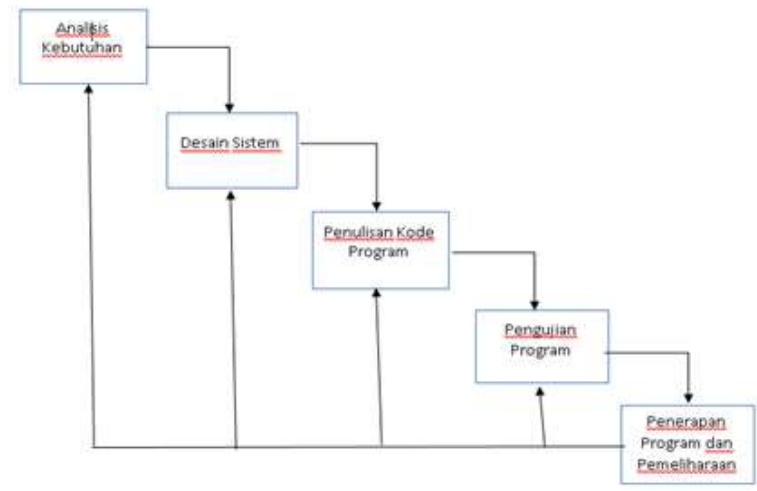

Gambar 3 Model Waterfall untuk Pengembangan Sistem 
Gambar 3 menunjukkan tahapan pengembangan aplikasi pada karya ilmiah ini. Langkah-langkahnya seperti analisis kebutuhan, desain sistem, penulisan kode program, pengujian program, penerapan program dan pemeliharaan. Berikut penjelasan dari masing-masing fungsi:

a. Analisis Kebutuhan

Analisis kebutuhan merupakan tahap pertama yang menjadi dasar proses pembuatan aplikasi selanjutnya. Kelancaran proses pembuatan aplikasi secara keseluruhan dan kelengkapan fitur aplikasi yang dihasilkan sangat tergantung pada hasil analisis kebutuhan.

b. Desain Sistem

Desain sistem merupakan tahap penyusunan proses, data, aliran proses dan hubungan antardata yang memenuhi kebutuhan sesuai dengan hasil analisis kebutuhan. Dokumentasi yang dihasilkan dari tahap desain sistem ini antara lain diagram hubungan Entitas Relationship Diagram (ERD), rancangan tampilan aplikasi dan flowchart diagram.

c. Penulisan Kode Program

Penulisan kode program merupakan tahap penerjemahan desain sistem yang telah dibuat ke dalam bentuk perintahperintah yang dimengerti komputer dengan menggunakan bahasa pemrograman dan database tertentu di atas platform yang sudah ditentukan.

d. Pengujian Program

Pengujian program dilakukan untuk memastikan bahwa aplikasi yang dibuat telah sesuai dengan desainnya dan semua fungsi dapat dipergunakan dengan baik tanpa ada kesalahan. Pengujian aplikasi dibuat dengan lengkap meliputi semua proses, kebutuhan dan pengendalian yang ada di dalam dokumen analisis kebutuhan dan desain sistem.

e. Penerapan Program dan Pemeliharaan Penerapan program merupakan tahap di mana pengembang menerapkan/menginstall aplikasi yang telah selesai dibuat dan diuji kepada pengguna.

\section{Implementasi dan Pengujian}

Implementasi adalah memindahkan logika program yang telah dibuat ke dalam bahasa yang dipilih. Dalam mengimplementasikan sistem tersebut membutuhkan tiga rangkaian dasar untuk mewujudkannya antara lain Hardware, Software dan Brainware (Abdurahman \& Riswaya, 2014).

Untuk mewujudkan implementasi berdasarkan dari tiga rangkaian dasar tersebut guna membangun sebuah sistem yang telah dibuat maka penerapan atau implementasi hardware dan software diwujudkan dengan mendefinisikan perangkat keras dan perangkat lunak yang akan digunakan, serta untuk menerapkan dasar implementasi brainware dilakukan dengan cara melakukan pengujian terhadap sistem yang telah di buat.

Implementasi antarmuka menampilkan tampilan pada halaman website yang akan digunakan oleh seorang admin dalam mengelola data informasi pariwisata serta tampilan pada halaman aplikasi android yang akan digunakan oleh pengguna sebagai media untuk mendapatkan informasi pariwisata. Berikut adalah beberapa tampilan antarmuka atau user interface dari aplikasi panduan Pariwisata di Kabupaten Banyuwangi.

Pada tahap ini, dalam pengujian yang dilakukan agar program website dan aplikasi siap digunakan oleh pengguna adalah dengan menguji program menggunakan metode black box testing. Hal ini dilakukan untuk mencari posisi kesalahan (error) dan memastikan keluaran yang dihasilkan sesuai keinginan (Handayani \& Yuniva, 2016).

Aplikasi panduan Pariwisata di Kabupaten Banyuwangi yang dibuat terdiri dari 2 bagian. Bagian pertama dibuat sebagai server yang bertujuan untuk menyediakan dan mengelola informasi pariwisata di Kabupaten Banyuwangi. Sedangkan bagian kedua merupakan aplikasi perangkat mobile berbasis Android ditujukan untuk pengguna yang membutuhkan informasi pariwisata di Kabupaten Banyuwangi.

Implementasi antarmuka menampilkan tampilan pada halaman website yang akan digunakan oleh seorang admin dalam mengelola data informasi pariwisata serta tampilan pada halaman aplikasi Android yang akan digunakan oleh pengguna sebagai media untuk mendapatkan informasi pariwisata. Beberapa tampilan antarmuka pengguna (user interface) dari aplikasi panduan Pariwisata di Kabupaten Banyuwangi ditunjukkan pada Gambar 4 sampai Gambar 6. 


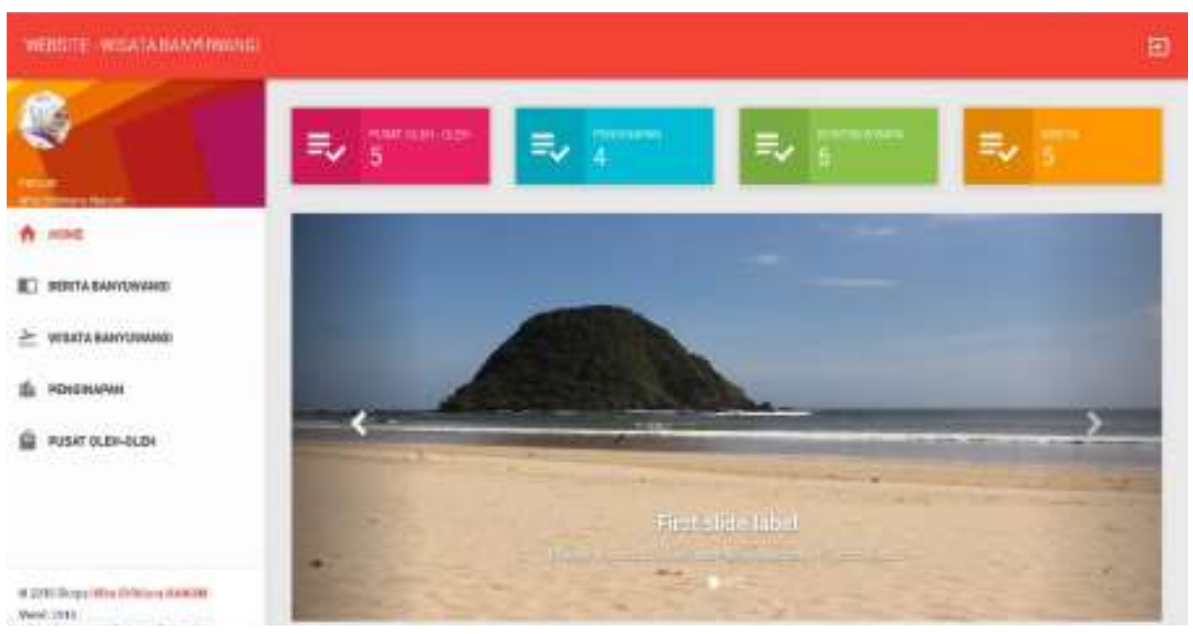

Gambar 4 Tampilan Utama Admin

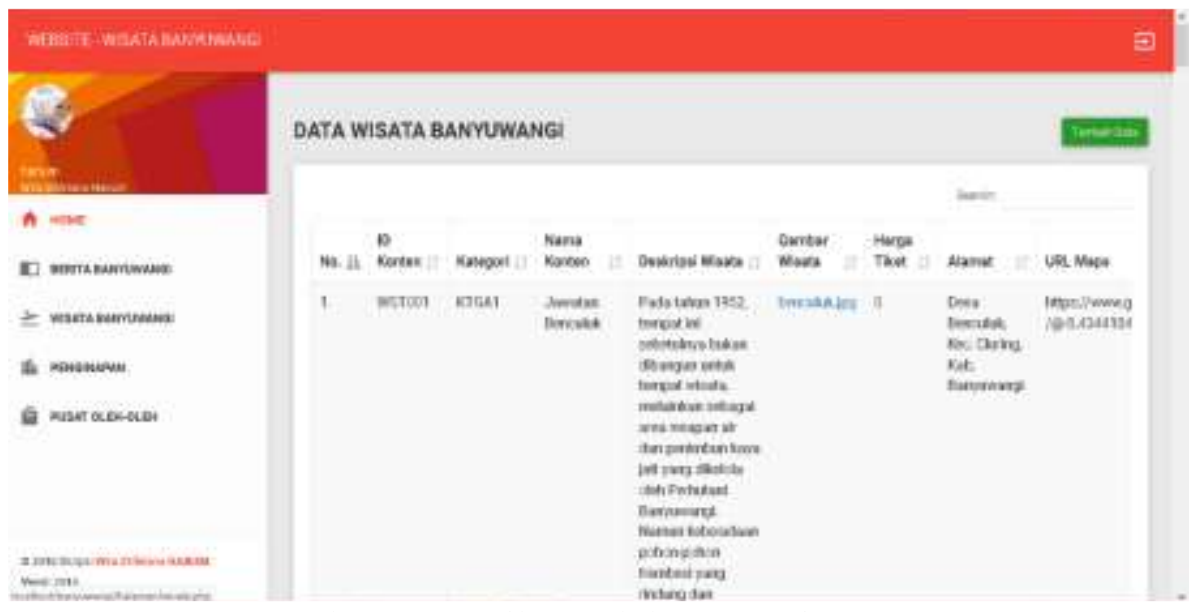

Gambar 5 Tampilan Kelola Data Wisata

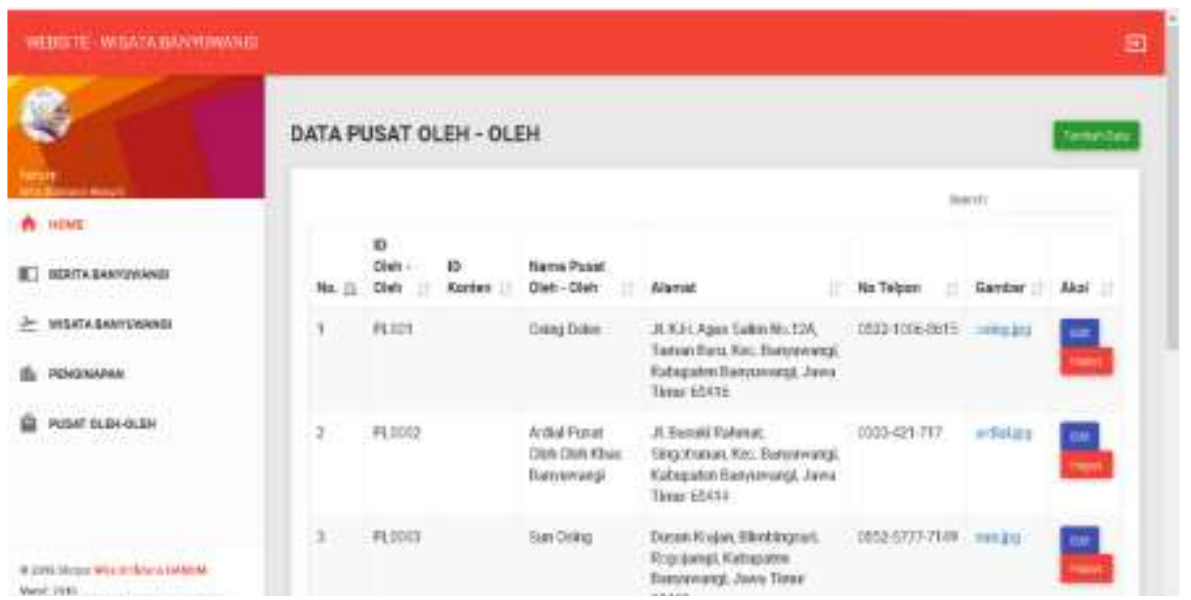

Gambar 6 Tampilan Kelola Data Pusat Oleh-Oleh

Pada tampilan antarmuka aplikasi untuk pengguna perangkat mobile Android memiliki tampilan yang ditunjukkan pada Gambar 7 sampai Gambar 9. Gambar 7 merupakan tampilan untuk menampilkan kategori wisata, tampilan ini akan ditampilkan ketika seorang pengguna aplikasi wisata banyuwangi memilih menu kategori. Pada halaman ini menampilkan 3 pilihan list wisata, seperti wisata alam, wisata buatan, wisata kuliner. Gambar 8 adalah tampilan halaman menu utama yang menampilkan 6 menu utama aplikasi wisata banyuwangi yang terdiri dari menu berita, menu kategori, menu penginapan dan menu pusat oleholeh, video dan tentang. Selanjutnya pada Gambar 9 menampilkan detail informasi wisata, halaman ini akan tampil ketika pengguna memilih salah satu 
data dari daftar wisata. Tampilan detail wisata menampilkan secara utuh informasi dari kategori wisata yang dipilih. Tabel 1 merupakan beberapa data hasil pengujian pada aplikasi panduan pariwisata di Kabupaten Banyuwangi.

$\leftarrow$ Kategori Wisata
Wisata Alam
Wisata Buatan
Wisata Kulinet

Gambar 7 Tampilan Kategori Wisata

$$
\text { Pariwisata Banyuwangi }
$$
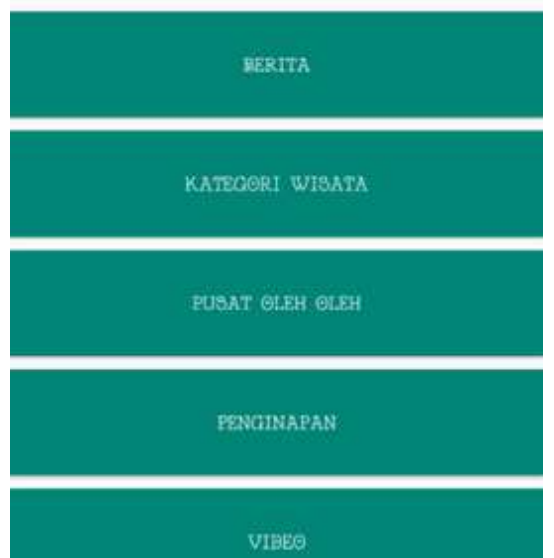

Gambar 8 Tampilan Menu Utama

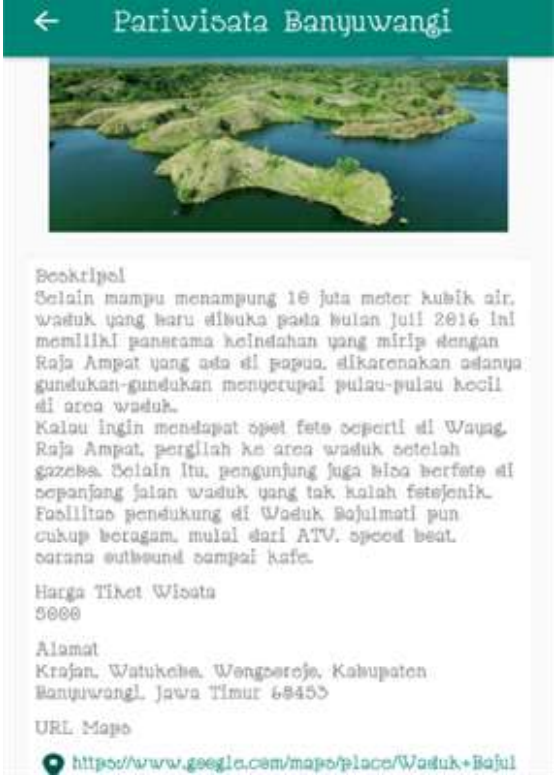

Gambar 9 Tampilan Detail Informasi Wisata

Tabel. 1 Pengujian Aplikasi Panduan Pariwisata

\begin{tabular}{|c|c|c|c|}
\hline $\begin{array}{l}\text { Masukan } \\
\text { pengujian }\end{array}$ & $\begin{array}{c}\text { Hasil yang } \\
\text { diharapkan }\end{array}$ & $\begin{array}{c}\text { Hasil } \\
\text { Pengamatan } \\
\end{array}$ & Kesimpulan \\
\hline Splashscreen & $\begin{array}{l}\text { Menampilkan } \\
\text { logo dan } \\
\text { membuka } \\
\text { menu utama } \\
\text { aplikasi }\end{array}$ & $\begin{array}{l}\text { Logo dan menu } \\
\text { utama aplikasi } \\
\text { dapat tampil }\end{array}$ & $\begin{array}{l}{[\checkmark] \text { Diterima }} \\
{[\text { ] Ditolak }}\end{array}$ \\
\hline $\begin{array}{l}\text { Menu utama } \\
\text { aplikasi }\end{array}$ & $\begin{array}{l}\text { Menampilkan } \\
\text { menu utama } \\
\text { aplikasi }\end{array}$ & $\begin{array}{l}\text { menu utama } \\
\text { aplikasi dapat } \\
\text { ditampilkan }\end{array}$ & $\begin{array}{l}{[\checkmark] \text { Diterima }} \\
{[\text { ] Ditolak }}\end{array}$ \\
\hline Menu berita & $\begin{array}{l}\text { Menampilkan } \\
\text { list berita }\end{array}$ & $\begin{array}{l}\text { List berita pada } \\
\text { menu berita } \\
\text { dapat } \\
\text { ditampilkan }\end{array}$ & $\begin{array}{l}{[\checkmark] \text { Diterima }} \\
{[\text { ] Ditolak }}\end{array}$ \\
\hline $\begin{array}{l}\text { Detail } \\
\text { informasi } \\
\text { berita }\end{array}$ & $\begin{array}{l}\text { menampilkan } \\
\text { informasi } \\
\text { berita yang di } \\
\text { pilih di menu } \\
\text { list berita } \\
\text { secara detail }\end{array}$ & $\begin{array}{l}\text { Informasi berita } \\
\text { yang dipilih pada } \\
\text { list berita dapat } \\
\text { ditampilkan } \\
\text { secara detail }\end{array}$ & $\begin{array}{l}{[\checkmark] \text { Diterima }} \\
{[\text { ] Ditolak }}\end{array}$ \\
\hline
\end{tabular}

\section{Kesimpulan}

Berdasarkan uraian-uraian serta analisis yang telah dilakukan pada bab-bab sebelumnya, terutama pada bagian perancangan dan implementasi dari sistem yang dibuat maka dapat ditarik kesimpulan, yaitu:

1. Dengan adanya aplikasi panduan Pariwisata di Kabupaten Banyuwangi memudahkan masyarat dan wisatawan dalam mendapatkan pengetahuan tentang informasi Pariwisata di Banyuwangi yang lebih cepat dengan media smartphone android dan informasi pariwisata yang tidak hanya sebatas wisata popular di Banyuwangi. 
2. Dalam mendukung masyarakat dan wisatawan untuk mendapatkan informasi yang dibutuhkan tentang Pariwisata di Banyuwangi penggunaan Smartphone android menjadi penting karena dapat memainkan perannya sebagai media informasi yang bisa mendukung untuk penyajian yang lebih lengkap dari sisi konten-konten informasi.

\section{Daftar Pustaka}

Abdurahman, H., \& Riswaya, A. R. (2014, Desember). Aplikasi Pinjaman Pembayaran Secara Kredit pada Bank Yudha Bakti. Jurnal Computech dan Bisnis, VIII, Nomor 2, 61-69.

Anggraini, G., Ardiyanty, S., \& Widiyanto, E. P. (2014, Oktober). Rancang Bangun Aplikasi Pengenalan Pariwisata Sumatera Selatan Berbasis Sistem Operasi Android. Jurnal Perkembangan dan Hasil Penelitian Ilmu Komputer, 242-249.

Ermatita. (2016, April). Analisa dan Perancangan Sistem Informasi Perpustakaan. Jurnal Sistem Informasi, VIII, Nomor 1, 966-977.

Gat, G. (2015). Perancangan Basis Data Perputakaan Sekolah dengan Menerapkan Model Data Relasional. Creative Information Technology Journal (CITEC Journal), 2(4), 304-315.

Haidar, F. (2017, Juni 2). Inovasi Pemerintahan Kabupaten Banyuwangi Melalui City Branding "The Sunrise Of Java" Sebagai Strategi Pemasaran Pariwisata. Jurnal Sosial Politik, V, Nomor 2, 332-344.
Handayani, D. S., \& Yuniva, I. (2016, Februari). Sistem Informasi Unit Kegiatan Siswa Pramuka Berbasis Web pada SMK Negeri 4 Kota Tangerang. Jurnal Sistem Informasi STMIK Antar Bangsa, V, Nomor 1, 27-33.

Hendini, A. (2016, Desember). Pemodelan UML Sistem Informasi Monitoring Penjualan dan Stok Barang (Studi Kasus: Distro Zhezha Pontianak). Jurnal Khatulistiwa Informatika, IV, Nomor 2, 107-116.

Mertayasa, D. M., \& Yambese, A. R. (2017, Januari). Sistem Infromasi Pariwisata Pantai Berbasis Web pada Dinas Pariwisata dan Ekonomi Kreatif Kabupaten Banggai Kepulauan. Jurnal Elektronik Sistem Informasi dan Komputer, III, Nomor 1, 51-61.

Muttaqin, I., Permana, I., \& Salisah, F. N. (2017, Februari). Aplikasi Navigasi Objek Wisata Kabupaten Lingga Berbasis Mobile. Jurnal Ilmiah Rekayasa dan Manajemen Sistem Informasi, III, Nomor 1, 1-10.

Sulihati, \& Andriyani. (2016, April). Aplikasi Akademik Online Berbasis Mobile Android pada Universitas Tama Jagakarsa. Jurnal Sains dan Teknologi Utama, XI, Nomor 1, 15-26.

Udayana, A. T., Wirawan, I. A., \& Sunarya, I. G. (2015). Pengembangan Aplikasi Panduan Pariwisata Berbasis Android di Kabupaten Klungkung. Jurnal Pendidikan Teknik Informatika, V, Nomor 1, 1-9. 